\title{
85641 - TESTE DA ESCADA HORIZONTAL: ANÁLISE DA REPRODUTIBILIDADE DOS ESCORES DE AVALIAÇÃO DA MARCHA EM MODELOS MURINOS
}

\author{
Pôster - Gerontologia
}

\author{
Lucas Athaydes Martins / Martins, LA / PUCRS; Aniuska Schiavo / Schiavo, A / PUCRS; \\ André Zanluchi / Zanluchi, A / PUCRS; Luísa Reichert / Reichert, L / PUCRS; \\ Caroline Borba da Silva / Borba da Silva, C / PUCRS; \\ Régis Gemerasca Mestriner / Mestriner, RG / PUCRS
}

Introdução: A capacidade de adaptar a marcha nos permite caminhar em diferentes circunstâncias, terrenos e com padrões de velocidades diferentes. A instabilidade durante a caminhada muda conforme o avanço da idade. Indivíduos idosos apresentam alterações de estabilidade corporal, mudanças nos padrões de marcha e perdas graduais de recursos cognitivos importantes para prevenir a ocorrência de quedas. No entanto, as bases neurobiológicas da adaptabilidade da marcha ainda não são totalmente compreendidas. Neste contexto, o teste da escada horizontal é amplamente utilizado para avaliação da adaptabilidade da marcha em modelos experimentais murinos, sua análise é realizada por meio de um escore de colocação das patas anteriores e posteriores, possibilitando qualificar e quantificar a coordenação sensório-motora durante a locomoção. No entanto, a confiabilidade da avaliação deste teste ainda não foi testada. Objetivo: Avaliar a reprodutibilidade e a consistência intra-avaliador e interavaliador do teste da escada horizontal, buscando elucidar os níveis de confiabilidade do teste. Método: Com o propósito de avaliar a concordância intra e inte-ravaliador, empregou-se 40 vídeos de murinos realizando o teste da escada horizontal (20 para ratos e 20 para camundongos), que foram analisados por 2 avaliadores independentes. Cada vídeo foi analisado duas vezes por cada um dos avaliadores, de modo cegado, totalizando 80 análises por avaliador. Para a análise estatística, empregou-se o teste de correlação intraclasse (ICC) e o coeficiente de concordância de Kappa, utilizando o software SPSS 17.0. Resultados: $\mathrm{Na}$ análise de concordância inter-avaliadores, verificou-se a existência de níveis variados de concordância geral para o teste, desde excelente até pobre, dependendo do nível de classificado. Já na análise de concordância intra-avaliadores, verificou-se valores muito semelhantes para todos os escores, o que revelou um alto grau de concordância entre as avaliações realizadas. Conclusão: Embora o teste da escada horizontal apresente concordância razoável para as análises intra-avaliador, a confiabilidade interavaliadores ainda é uma questão a ser melhor estudada. Portanto, aconselha-se que um único avaliador deve realizar a análises de todos os vídeos do teste da escada horizontal, visando assim aumentar o grau de confiabilidade dos resultados obtidos. 